\title{
Elastic-Plastic Analysis of Surrounding Rock in Deep Roadway Considering Shear Dilatancy Property under Non-Uniform Stress Field
}

\author{
Li Chuan-ming ${ }^{1,2}$, Shi Wen-bao ${ }^{1,2, *}$, Liu Wan-rong ${ }^{3}$ and Feng Rui-min ${ }^{4}$ \\ ${ }^{1}$ School of Resource and safety Engineering, Anhui University of Science and Technology, Huainan, Anhui 232001,China \\ ${ }^{2}$ Anhui Province Key Laboratory of Mining Response and Disaster Prevention and Control in Deep Coal Mine, Anhui University of \\ Science and Technology, Huainan Anhui 232001, China \\ ${ }^{3}$ School of Physics Science \& Information Engineering, Liaocheng University, Liaocheng, Shandong 252059, China \\ ${ }^{4}$ Department of Mining and Mineral Resources Engineering, Southern Illinois University, Carbondale, Illinois 62901, United States
}

Received 2 May 2017; Accepted 11 August 2017

\begin{abstract}
The surrounding rock of deep engineering roadway is under the complicated mechanical environment of non-uniform stress distribution, and the stress mechanical model of uniform distribution is obviously different from the surrounding rock of roadway in real stress state. Thus, accurately evaluating the stress and deformation state of surrounding rock is infeasible in non-uniform stress field when employing the mechanical model developed for uniform stress conditions. To reflect the real mechanical state of the roadway surrounding rock accurately and calculate the radius of the plastic zone in roadway surrounding rock precisely, a mechanical model of roadway surrounding rock under non-uniform stress conditions was established in this study based on unified strength theory. One floor roadway of 1231 (1) working face in Panyi coal mine of Huainan coal field was considered as an example. The influences of side pressure coefficient and intermediate principal stress on the scope of the plastic zone in surrounding rock were analyzed. The effect of shear dilatancy property on the deformation and failure process of surrounding rock was discussed, and the field monitoring and verification of the scope of the plastic zone in surrounding rock were conducted on the floor roadways of 1231 (1) and 1252 (1) working face in this mine. Research results indicate that the displacement of the plastic zone enlarges by nearly thrice while the side pressure coefficient increases, and the radius of the plastic zone in roadway surrounding rock in the vertical direction is obviously larger than that in the horizontal direction, which reflects an anisotropic characteristic of the surrounding rock of deep roadway. The displacement of the plastic zone in the surrounding rock enlarges by at least $60 \%$ while the shear dilatancy parameter increases, but the morphological change of the plastic zone is minor. Furthermore, the displacement of the plastic zone in the surrounding rock reduces by nearly $35 \%$ while the intermediate principal stress increases. Field test results of the scope of the plastic zone in roadway surrounding rock through borehole peering under different side pressure coefficients match well with the results from theoretical calculation, which verifies the applicability and accuracy of the mechanical model of roadway surrounding rock established in this study. The research results can provide theoretical references for stability analysis and support the design of the surrounding rock of deep roadway.
\end{abstract}

Keywords: Non-Uniform Stress Field; Unified Strength Theory; Shear Dilatancy Property; Elastic-Plastic Analysis

\section{Introduction}

Roadway, running through all links of underground coal mining, is the lifeblood of coal mine production, transportation, and ventilation; and normal roadway excavation and maintenance are the key for the safe and efficient production of a coal mine. Coal mine roadway increases by hundreds of thousands of meters annually; thus, supporting work load for roadway surrounding rock is quite heavy. The original balanced 3D stress state of the surrounding rock is transformed into a $2 \mathrm{D}$ stress state after roadway excavation. Stress redistribution causes deformation, displacement, and even failure of rock masses near the roadway, and an accurate evaluation of the stress

\footnotetext{
*E-mail address: wenbaoshi @163.com

ISSN: $1791-2377 @ 2017$ Eastern Macedonia and Thrace Institute of Technology. All rights reserved. doi:10.25103/jestr.104.03
}

state of roadway surrounding rock is the basis and precondition for supporting design of mine roadways.

Most coal mine roadways are in the sedimentary formation due to the occurrence characteristics of the coal seam. The stratiform characteristics of the roadway surrounding rock are apparent, and the stress state of roadway surrounding rock presents obvious characteristics of the non-uniform distribution. In recent years, shallow coal resources are reduced daily due to enhanced coal mining intensity. Human mining activities gradually transfer to a deep part, and many mines enter the deep mining phase. Compared with shallow part, the surrounding rock in deep part is under extremely severe mechanical environment, generally accompanied by uncontrollable dangerous factors, such as high ground stress, ground temperature, and karst water pressure; thus, the mechanical environment of the surrounding rock of deep roadway becomes complicated with obvious non-uniform stress distribution characteristics; 
consequently, the control difficulty of stabilizing roadway surrounding rock is significantly magnified [1],[2].

Engineering technicians and researchers aim to maintain long-term roadway stability and unblocked state by adopting all kinds of supporting design methods to ensure the stability of the roadway surrounding rock, such as engineering analogical, displacement feedback, and broken-rock circle supporting load design methods [3],[4],[5]. An empirical formula formed by summarizing in-situ engineering practices provides a favorable application effect on the shallow part or roadway support with good engineering geological conditions. However, its application in the deep part and roadway support under complicated conditions is questionable. Establishment of a mechanical model for analyzing the mechanical properties of the roadway surrounding rock can provide a universal theoretical foundation for roadway support. Effectively reflecting the real stress state of roadway surrounding rock with certain limitations is difficult for the conventional mechanical models of uniformly distributed stress. Therefore, establishing a mechanical model, which can effectively reflect the real stress state of roadway surrounding rock and accurately describe the mechanical state of roadway surrounding rock, remains a problem that requires in-depth research.

A mechanical model of roadway surrounding rock under non-uniformly distributed stress conditions has been established in this study, and the deformation and failure features of roadway surrounding rock are investigated theoretically and practically.

\section{State of the art}

Numerous scholars have conducted considerable theoretical research on the mechanical characteristics of roadway surrounding rock and have obtained abundant research results [6], [7], [8], [9], [10], [11], [12]. Maleki et al. [13] conducted an elastic-plastic analysis of roadway surrounding rock and effectively evaluated roadway stability based on the elastoplastic-viscoplastic constitutive model and the time effect of the mechanical environment of roadway surrounding rock. According to the different mechanical environments of roadway surrounding rock, Cantieni et al. [14] constructed the corresponding calculation model, discussed the influence of ground stress on the elastic-plastic analysis results of roadway surrounding rock in detail, and then proposed reasonable support measures. Debernardi et al. [15] established a new SHELVIP model, investigated the stress and deformation characteristics of roadway surrounding rock in detail, and analyzed the reasonability of this model according to the stress and deformation characteristics of roadway surrounding rock and shear dilatancy characteristics. Taking moisture-containing roadway as research object, Fahimifar et al. [16] considered the influence of pore water pressure on roadways and obtained the elastic-plastic solution of roadway surrounding rock. Zhu et al. [17], [18] analyzed the stress distribution and deformation characteristics of roadway surrounding rock given that the surrounding rock was under uniformly distributed stress field and based on stress-hardening characteristics in front of surrounding rock peak. Liu et al. [19] considered shear dilatancy characteristics under the isobaric situation and obtained elastic-plastic solution. Under an anisobaric situation, Sharan et al. [20] used HookerBrown criterion in analyzing the stress and displacement distribution laws of surrounding rock in the circular roadway. $\mathrm{Xu}$ et al. [21] introduced intermediate principal stress and shear dilatancy coefficients to obtain new stress and displacement solutions of roadway surrounding rock. Zhao [22] conducted the elastic-plastic analysis of cemented weak plane-containing surrounding rock considering the shear dilatancy characteristics under the anisobaric situation. The stress state of roadway surrounding rock was jointly influenced by multiple parameters, such as stress field and the mechanical properties of surrounding rock. Previous studies usually simplified and even neglected certain parameters for analytic calculation; thus, these studies could not sufficiently reflect the real mechanical environment of surrounding rock. The stress distribution characteristics of roadway surrounding rock solved through theoretical analysis are significantly different from that of the actual situation. At present, assuming the mechanical environment of the surrounding rock in the elastic-plastic analysis of roadway surrounding rock to reflect its real mechanical characteristics is difficult. The selection of a calculation model that agrees well with the real mechanical environment of the surrounding rock is necessary to obtain further accurate mechanical characteristics of roadway surrounding rock.

Based on unified strength theory, the mechanical model of roadway surrounding rock under non-uniformly distributed stress state was established according to the engineering geological conditions of the floor roadway of 1231 (1) working face in the eastern area of Panyi coal mine. The mechanical state of roadway surrounding rock was analyzed, and the elastic-plastic solution of roadway surrounding rock closer to reality was obtained. The field monitoring and verification of floor roadways in 1231 (1) and 1252 (1) working faces in the eastern area of Panyi coal mine were conducted, thus providing the additional beneficial theoretical basis for roadway supporting design and parameter optimization.

The rest of this study is organized as follows: Section 3 describes the theoretical research scheme and basic equations describing stress state, which should be met by roadway surrounding rock. Section 4 discusses and analyzes the theoretical analysis results. The research conclusions are drawn in Section 5.

\section{Methodology}

\subsection{Unified strength theory}

Unified strength theory [15] indicates that tensile stress is negative, and compressive stress is positive. In addition, $b$ is assumed to be the action coefficient of the intermediate principal stress. $\sigma_{1}, \sigma_{2}$ and $\sigma_{3}$ are the maximum, intermediate, and minimum principal stresses of surrounding rock, respectively. $c$ and $\varphi$ are the cohesion and internal friction angle of the surrounding rock, correspondingly. The following two equations should be satisfied under the plastic yield state of roadway surrounding rock:

$$
\text { When } \sigma_{2} \leq \frac{\sigma_{1}+\sigma_{3}}{2}-\frac{\sigma_{1}-\sigma_{3}}{2} \sin \phi \text {, the stress state of }
$$
surrounding rock should meet: 
$\left\{\begin{array}{l}\varepsilon_{\mathrm{r}}^{e}=\frac{1}{2 G}\left[(1-\mu)\left(\sigma_{\gamma}-p_{0}\right)-\mu\left(\sigma_{\theta}-p_{0}\right)\right] \\ \varepsilon_{\theta}^{e}=\frac{1}{2 G}\left[(1-\mu)\left(\sigma_{\theta}-p_{0}\right)-\mu\left(\sigma_{\gamma}-p_{0}\right)\right]\end{array}\right.$

When $\sigma_{2} \geq \frac{\sigma_{1}+\sigma_{3}}{2}-\frac{\sigma_{1}-\sigma_{3}}{2} \sin \phi$, the stress state of surrounding rock should satisfy:

$\frac{1+\sin \phi}{1+b}\left(\sigma_{1}+b \sigma_{2}\right)-\sigma_{3}(1-\sin \phi)=2 c \cos \phi$

When $b=0$, the expression of unified strength theory is transformed into the expression of Mohr-Coulomb strength criterion. When $b=1$, the expression of unified strength theory is transformed into the expression of double-shear strength theory. When $0<b<1$, the expression of unified strength theory is transformed into the expression of other strength theories.

The radial stress of the plastic zone in roadway surrounding rock is $\sigma_{r}$, and the intermediate principal stress

$\sigma_{z}$ and the circumferential stress $\sigma_{\theta}$ should meet $\sigma_{\theta} \geq \sigma_{z} \geq \sigma_{r}$. Thus, the following equations are obtained.

$\left\{\begin{array}{l}\sigma_{1}=\sigma_{\theta} \\ \sigma_{2}=\sigma_{\mathrm{z}} \\ \sigma_{3}=\sigma_{\mathrm{r}}\end{array}\right.$

Then, the stress state of roadway surrounding rock under plane strain state meets Equation (1).

$\frac{1-\sin \phi}{1+b}(\mu b+1) \sigma_{\theta}-\left[\left(1+\sin \phi-b \mu \frac{1-\sin \phi}{1+b}\right)\right] \sigma_{r}=2 c \cos \phi$

where $\mu$ is the Poisson's ratio.

Equation (3) is further simplified to:

$\sigma_{\theta}-A \sigma_{r}-B=0$

where

$\left\{\begin{array}{l}A=\frac{(1+b-b \mu)+\sin \phi(1-b+b \mu)}{(1-\sin \phi)(b \mu+1)} \\ B=\frac{2 c \cos \phi(1+b)}{(1-\sin \phi)(b \mu+1)}\end{array}\right.$

3.2 Mechanical model of roadway surrounding rock

The surrounding rock stress is re-distributed after roadway excavation, and the elastic and plastic zones are formed in roadway surrounding rock. The roadway cross section is assumed to be circular with infinite length in a mechanical model of the roadway. Meanwhile, the volume change of surrounding rock in the plastic phase is 0 , and its own weight is neglected. The mechanical model is illustrated in Fig. 1, where $p_{0}$ is the initial ground stress in the vertical direction, $\lambda p_{0}$ is the initial ground stress in horizontal direction, $\lambda$ is the side pressure coefficient, and $p_{\mathrm{i}}$ is the supporting resistance; moreover, $a$ is the roadway radius, $R$ is the radius of the plastic zone, $r$ is the radius from any point in surrounding rock to the center of a circle, and $\theta$ is the included angle between the $\operatorname{radius}(r)$ and polar axis in the horizontal direction.

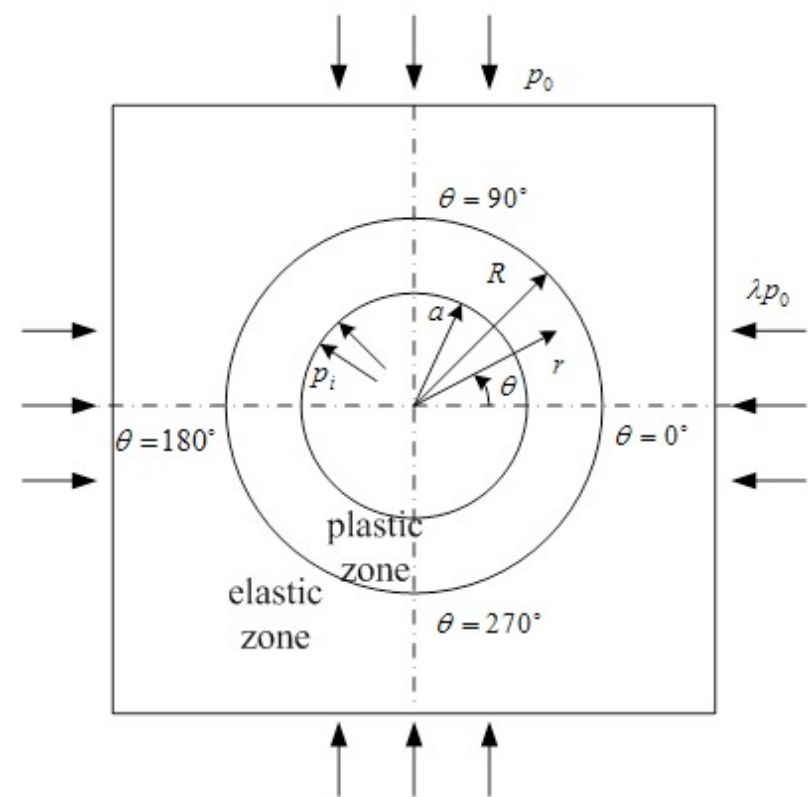

Fig. 1. Mechanical model of circular roadway

A yield criterion was used in this study to analyze the elastic-plastic of roadway surrounding rock. The elasticplastic state of surrounding rock was determined through its bearing stress according to unified strength theory and the mechanical model of circular roadway. Furthermore, the surrounding rock is under the plastic state when the surrounding rock stress meets the expression of unified strength theory. The plastic radius of surrounding rock is then determined by equilibrium equations, and the distribution characteristics of stress, strain, and displacement of surrounding rock are obtained.

\subsection{Stress of the elastic zone in roadway surrounding} rock

Circular roadway could be decomposed into the superposition of uniform and unidirectional compressive stress field under bidirectional anisobaric stress field, as shown in Fig. 2.

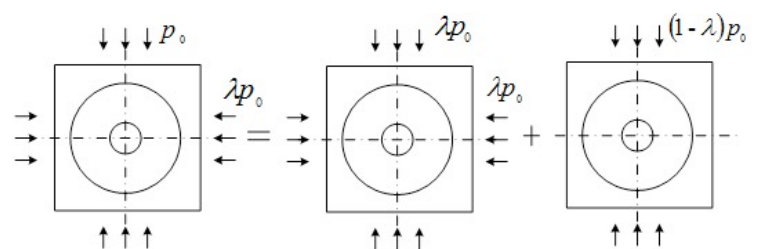

Fig. 2. Stress field of surrounding rock

In this study, $\sigma_{R}$ is assumed to be the radial stress at the elastic-plastic junction in roadway surrounding rock, $\sigma_{R}$ is considered the supporting resistance of surrounding rock in the elastic zone, and the stress expression in the elastic zone in roadway surrounding rock when the surrounding rock is under the effect of uniform pressure $\lambda p_{0}$ is as follows: 


$$
\left\{\begin{array}{l}
\sigma_{\mathrm{r}}=\lambda p_{0}\left(1-\frac{R^{2}}{r^{2}}\right)+\sigma_{R} \frac{R^{2}}{r^{2}} \\
\sigma_{\theta}=\lambda p_{0}\left(1+\frac{R^{2}}{r^{2}}\right)-\sigma_{R} \frac{R^{2}}{r^{2}}
\end{array}\right.
$$

When the surrounding rock is under the effect of unilateral pressure $(1-\lambda) p_{0}$, the stress expression in the elastic zone in roadway surrounding rock is as follows:

$$
\left\{\begin{array}{l}
\sigma_{\mathrm{r}}=\frac{1}{2}(1-\lambda) p_{0}\left(1-\frac{R^{2}}{r^{2}}\right)-\frac{1}{2}(1-\lambda) p_{0} \cos 2 \theta\left(1-4 \frac{R^{2}}{r^{2}}+3 \frac{R^{4}}{r^{4}}\right) \\
\sigma_{\theta}=\frac{1}{2}(1-\lambda) p_{0}\left(1+\frac{R^{2}}{r^{2}}\right)+\frac{1}{2}(1-\lambda) p_{0} \cos 2 \theta\left(1+3 \frac{R^{4}}{r^{4}}\right) \\
\tau_{r \theta}=\frac{1}{2}(1-\lambda) p_{0} \sin 2 \theta\left(1+2 \frac{R^{2}}{r^{2}}-3 \frac{R^{4}}{r^{4}}\right)
\end{array}\right.
$$

When the surrounding rock is under non-uniform field with side pressure coefficient of $\lambda$, the stress expression in the elastic zone in roadway surrounding rock is as follows:

$$
\left\{\begin{array}{l}
\sigma_{\mathrm{r}}=\frac{1}{2}(1+\lambda) p_{0}\left(1-\frac{R^{2}}{r^{2}}\right)+\sigma_{R} \frac{R^{2}}{r^{2}}-\frac{1}{2}(1-\lambda) p_{0} \cos 2 \theta\left(1-4 \frac{R^{2}}{r^{2}}+3 \frac{R^{4}}{r^{4}}\right) \\
\sigma_{\theta}=\frac{1}{2}(1+\lambda) p_{0}\left(1+\frac{R^{2}}{r^{2}}\right)-\sigma_{R} \frac{R^{2}}{r^{2}}+\frac{1}{2}(1-\lambda) p_{0} \cos 2 \theta\left(1+3 \frac{R^{4}}{r^{4}}\right) \\
\tau_{r \theta}=\frac{1}{2}(1-\lambda) p_{0} \sin 2 \theta\left(1+2 \frac{R^{2}}{r^{2}}-3 \frac{R^{4}}{r^{4}}\right)
\end{array}\right.
$$

At junction $r=R$ between elastic and plastic zones in roadway surrounding rock, we have:

$$
\left\{\begin{array}{l}
\sigma_{\mathrm{r}}=\sigma_{R} \\
\sigma_{\theta}=(1+\lambda) p_{0}-\sigma_{R}+2(1-\lambda) p_{0} \cos 2 \theta
\end{array}\right.
$$

The following equation can be obtained by substituting Equation (9) into Equation (5):

$\sigma_{R}=\frac{(1+\lambda) p_{0}+2(1-\lambda) p_{0} \cos 2 \theta-B}{A+1}$

\subsection{Displacement of the elastic zone in roadway} surrounding rock

The surrounding rock strain in the elastic zone meets constitutive equations:

$$
\left\{\begin{array}{l}
\varepsilon_{\mathrm{r}}=\frac{1-\mu^{2}}{E}\left(\sigma_{\mathrm{r}}-\frac{\mu}{1-\mu} \sigma_{\theta}\right) \\
\varepsilon_{\theta}=\frac{1-\mu^{2}}{E}\left(\sigma_{\theta}-\frac{\mu}{1-\mu} \sigma_{\mathrm{r}}\right) \\
\gamma_{r \theta}=\frac{2(1+\mu)}{E} \tau_{r \theta}
\end{array}\right.
$$

where $\varepsilon_{r}$ is the radial strain in the elastic zone, $\varepsilon_{\theta}$ is the circumferential strain in the elastic zone, $\gamma_{r \theta}$ is the shear strain, and $\tau_{r \theta}$ is the shear force.

The surrounding rock in the elastic zone should meet geometric equation.

$$
\left\{\begin{array}{l}
\varepsilon_{\mathrm{r}}=\frac{\partial u_{r}}{\partial r} \\
\varepsilon_{\theta}=\frac{u_{r}}{r}+\frac{1}{r} \frac{\partial u_{\theta}}{\partial \theta} \\
\gamma_{r \theta}=\frac{1}{r} \frac{\partial u_{r}}{\partial \theta}+\frac{\partial u_{\theta}}{\partial r}-\frac{u_{\theta}}{r}
\end{array}\right.
$$

where $u_{r}$ is the radial displacement.

When Equation (8) is substituted into Equations (11) and (12) and when $r \rightarrow \infty$, radial displacement is $u_{r}=0$, and the circumferential displacement is $u_{\theta}=0$. Then, the radial displacement in the elastic zone in roadway surrounding rock can be obtained.

$$
u_{\mathrm{r}}=\frac{(1+\mu) R^{2}}{E r}\left\{\sigma_{\mathrm{R}}-\frac{1}{2} p_{0}(1+\lambda)-p_{0}(1-\lambda)\left[\frac{R^{2}}{2 r^{2}}-2(1-\mu)\right] \cos 2 \theta\right\}
$$

3.5 Radius of the plastic zone and stress distribution characteristics of roadway surrounding rock

The surrounding rock stress in the plastic zone should meet the equilibrium equation as follows:

$r \frac{d \sigma_{r}}{d r}+\sigma_{r}-\sigma_{\theta}=0$

The expressions of tangential $\sigma_{\theta \mathrm{p}}$ and radial stress $\sigma_{\mathrm{rp}}$ in the plastic zone in surrounding rock can be obtained through simultaneous Equations (5) and (14). $\sigma_{\theta \mathrm{p}}$ and $\sigma_{\mathrm{rp}}$ meet the following equation:

$\left\{\begin{array}{l}\sigma_{\mathrm{r} p}=C r^{A-1}-c \cot \phi \\ \sigma_{\theta p}=A \cdot C r^{A-1}-c \cot \phi\end{array}\right.$

where $C$ is the integration constant.

Equation (15) meets the condition $\sigma_{r}(R)=\sigma_{R}$ when $r=R$. $C$ can be expressed by the following equation:

$C=\left(\sigma_{R}+c \cot \phi\right) R^{1-A}$

The tangential $\sigma_{\theta}$ and radial stress $\sigma_{\mathrm{r}}$ in the plastic zone in surrounding rock should meet:

$\left\{\begin{array}{l}\sigma_{\mathrm{r} p}=\left(\sigma_{R}+c \cot \phi\right)\left(\frac{r}{R}\right)^{A-1}-c \cot \phi \\ \sigma_{\theta p}=A \cdot\left(\sigma_{R}+c \cot \phi\right)\left(\frac{r}{R}\right)^{A-1}-c \cot \phi\end{array}\right.$

Equation (17) meets the condition $\sigma_{r}(a)=p_{i}$ when $r=a$. The radial stress $\sigma_{\text {rp }}$ in the plastic zone in surrounding rock should meet: 
$\left(\sigma_{R}+c \cot \phi\right)\left(\frac{a}{R}\right)^{A-1}-c \cot \phi=p_{i}$

The expression of radius $R$ in the plastic zone in roadway surrounding rock can be obtained by substituting Equation (10) into Equation (18):

$R=a \cdot\left[\frac{\frac{(1+\lambda) p_{0}+2(1-\lambda) p_{0} \cos 2 \theta-B}{A+1}+c \cot \varphi}{p_{i}+c \cot \varphi}\right]^{\frac{1}{1-1}}$

3.6 Displacement of the plastic zone in roadway surrounding rock

Elastic strains $\varepsilon_{\mathrm{r}}^{\mathrm{e}}$ and $\varepsilon_{\theta}^{\mathrm{e}}$ in the plastic zone in roadway surrounding rock meet:

$$
\left\{\begin{array}{l}
\varepsilon_{\mathrm{r}}^{e}=\frac{1}{2 G}\left[(1-\mu)\left(\sigma_{\gamma}-p_{0}\right)-\mu\left(\sigma_{\theta}-p_{0}\right)\right] \\
\varepsilon_{\theta}^{e}=\frac{1}{2 G}\left[(1-\mu)\left(\sigma_{\theta}-p_{0}\right)-\mu\left(\sigma_{\gamma}-p_{0}\right)\right]
\end{array}\right.
$$

where $G$ is the shear modulus.

Plastic strains $\varepsilon_{\mathrm{r}}^{\mathrm{p}}$ and $\varepsilon_{\theta}^{\mathrm{p}}$ in the plastic zone in roadway surrounding rock meet the non-associated flow rule:

$\varepsilon_{\mathrm{r}}^{p}+\eta \varepsilon_{\theta}^{p}=0$

where $\eta$ is the material shear dilatancy coefficient.

$\eta=\frac{1+\sin \psi}{1-\sin \psi}$

where $\Psi$ is the shear dilatancy angle of surrounding rock in the plastic zone and is generally smaller than or equal to the internal friction angle.

The total strain in the plastic zone is the sum of the elastic and plastic strains, and the expressions of total strains $\varepsilon_{\mathrm{r}}$ and $\varepsilon_{\theta}$ in the plastic zone can be obtained through Equation (21):

$\eta \varepsilon_{\theta}+\varepsilon_{\mathrm{r}}=\eta \varepsilon_{\theta}^{\mathrm{e}}+\varepsilon_{\mathrm{r}}^{e}$

The roadway surrounding rock in the plastic zone meets the following geometric equation:

$\left\{\begin{array}{l}\varepsilon_{\mathrm{r}}=\frac{\partial u}{\partial r} \\ \varepsilon_{\theta}=\frac{u}{r}\end{array}\right.$

The following equation can be obtained through simultaneous Equations (17), (20), (23), and (24):

$$
u_{p}=u_{R}\left(\frac{R}{r}\right)^{\eta}+\frac{1}{2 G} \frac{1}{r^{\eta}}\left[T_{1}\left(r^{\eta+A}-R^{\eta+A}\right)+T_{2}\left(r^{\eta+1}-R^{\eta+1}\right)\right]
$$

where

$$
\begin{aligned}
& T_{1}=\frac{\left(p_{i}+c \cot \phi\right)[1-(1+A) \mu+\eta(A-A \mu-\mu)]}{(\eta+A) a^{A-1}} \\
& T_{2}=-\left(p_{0}+c \cot \phi\right)(1-2 \mu) \\
& u_{\mathrm{R}}=\frac{(1+\mu) R}{E}\left\{\sigma_{\mathrm{R}}-p_{0}(1-\lambda)\left(2 \mu-\frac{3}{2}\right) \cos 2 \theta-\frac{1}{2} p_{0}(1+\lambda)\right\}
\end{aligned}
$$

The expression of roadway wall displacement $u_{0}$ can be further obtained:

$u_{0}=u_{R}\left(\frac{R}{r_{\mathrm{a}}}\right)^{\eta}+\frac{1}{2 G} \frac{1}{a^{\eta}}\left[T_{1}\left(a^{\eta+A}-R^{\eta+A}\right)+T_{2}\left(a^{\eta+1}-R^{\eta+1}\right)\right]$

\section{Result Analysis and Discussion}

Panyi coal mine of Huainan mining area in China is located in the hinge zone between the southeast wing of Panji anticline and east pitch. The overall morphology is folding structure and passes through Panji anticline, which turns from the axial east-west direction toward the southeast direction in the whole zone. The primary mining coal seams are $\# 13-1, \# 11, \# 8, \# 6$, \#4, and \#1 coals. The main horizontal systems of shaft I are all arranged on the floor of \#11 coal, and its horizontal elevation is $-850 \mathrm{~m}$. The floor roadway in 1231 (1) working face was $20 \mathrm{~m}$ below the haulage roadway in 1231 (1) working face as a covering roadway for the above haulage roadway. The floor roadway of 1231 (1) working face in the eastern area of Panyi coal mine was approximately circular. Its equivalent radius was $r_{\mathrm{a}}=2 \mathrm{~m}$, and the vertical stress borne by the roadway was $p_{0}=19.2 \mathrm{MPa}$. The mechanical parameters of roadway surrounding rock measured through field sampling and laboratory test are shear modulus $G=9.8 \mathrm{GPa}$, internal friction angle $\varphi=30^{\circ}$, and cohesion $c=2.2 \mathrm{MPa}$. The influences of side pressure coefficient and other relevant factors on the mechanical characteristics of surrounding rock has been studied.

4.1 Influencing analysis the of different side pressure coefficients and intermediate principal stress on the scope of the plastic zone

When intermediate principal stress coefficients were taken as $b=0,0.5,1.0$, the radius distributions of the plastic zone under different side pressure coefficients $(\lambda=0.5, \lambda=1, \lambda=1.5)$ were analyzed. The results are illustrated in Fig. 3. 


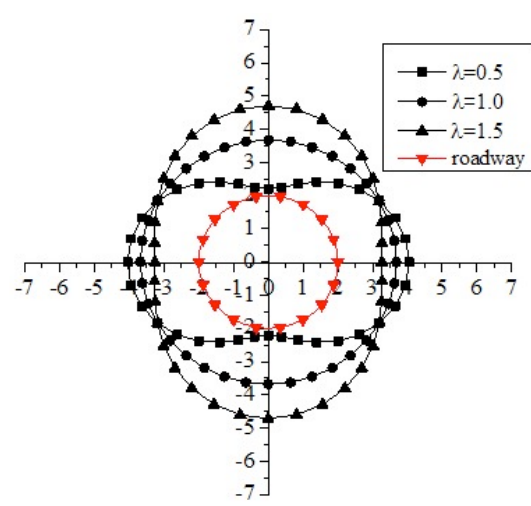

(a)

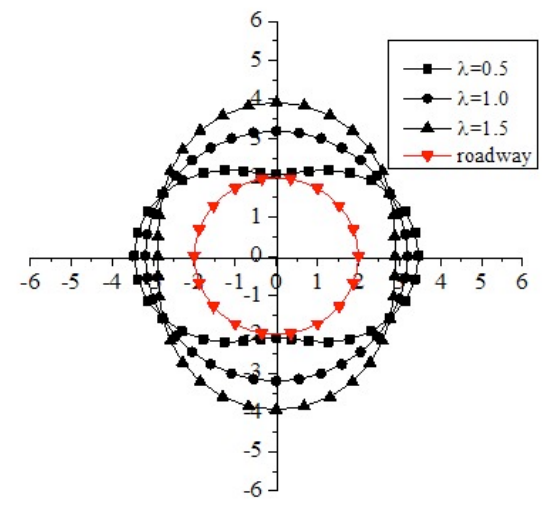

(b)

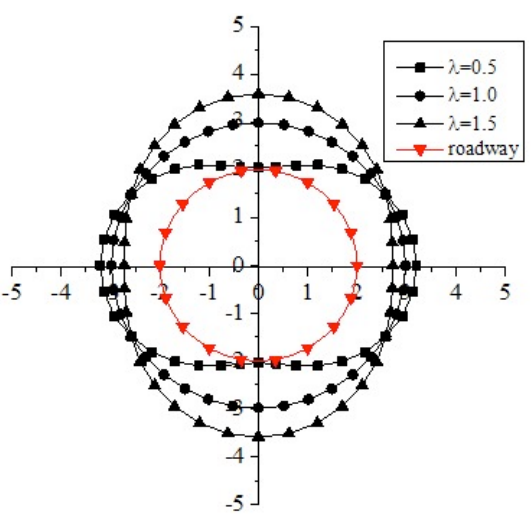

(c)

Fig. 3. Radius distribution of plastic zone in roadway surrounding rock under different side pressure coefficients and intermediate principal stress coefficients. (a) $b=0$. (b) $b=0.5$.(c) $b=1.0$

In Fig. 3, side pressure and intermediate principal stress coefficients significantly influence the radius of the plastic zone. When intermediate principal stress remains unchanged, the radius of the plastic zone is reduced along the $\theta=0^{\circ}$ direction while the side pressure coefficient increases. However, the radius of the plastic zone increases along the $\theta=90^{\circ}$ direction. Given the change in the side pressure coefficient, the radius of the plastic zone of the whole roadway surrounding rock is changed and shows obvious anisotropy.

When the side pressure coefficient is unchanged, the radius of the plastic zone is reduced as the intermediate principal stress increases along the $\theta=0^{\circ}$ and $\theta=90^{\circ}$ directions. The scope shape of the radius of the plastic zone is basically unchanged.

When $b=0$ and the side pressure coefficient increases from 0.5 to 1.5 , the radius of the plastic zone along the $\theta=0^{\circ}$ and the $\theta=90^{\circ}$ directions reduces by $18.5 \%$ and by $45.2 \%$, respectively. When $b=0.5$ and the side pressure coefficient increases from 0.5 to 1.5 , the radius of the plastic zone along the $\theta=0^{\circ}$ direction is reduced by $16.3 \%$ and by $46.6 \%$ along the $\theta=90^{\circ}$ direction. When $b=1.0$ and the side pressure coefficient increases from 0.5 to 1.5 , the radius of the plastic zone along the $\theta=0^{\circ}$ direction increases by $15.1 \%$ and by $43.3 \%$ along the $\theta=90^{\circ}$ direction. Thus, the change value of the radius of the plastic zone is much greater along the $\theta=90^{\circ}$ direction than that along the $\theta=0^{\circ}$ direction. Thus, the change is significant.

When $\lambda=0.5, \lambda=1$, and $\lambda=1.5$ and intermediate principal stress is increased from 0 to 1.0 , the radius of the plastic zone along the $\theta=0^{\circ}$ direction is reduced by $19.1 \%, 18.5 \%$, and $16.7 \%$ and the radius of the plastic zone along the $\theta=90^{\circ}$ direction is reduced by $15.2 \%, 14.5 \%$, and $13.7 \%$, correspondingly.

4.2 Influencing analysis of the different side pressure coefficients and shear dilatancy parameters on the displacement of plastic zone

The displacements of two roadway walls when $\theta=0^{\circ}$ or $\theta=180^{\circ}$ are analyzed. These displacements could be known using Equation (22) of shear dilatancy parameter when the shear dilatancy angle is $0^{\circ}$, shear dilatancy parameter is $\eta=1$, shear dilatancy angle is $30^{\circ}$, and shear dilatancy parameter is $\eta=3$. When intermediate principal stress is 0 , the control variable method can be used to analyze the influences of the different side pressure coefficients and shear dilatancy parameters on the displacement distribution of surrounding rock according to Mohr-Coulomb criterion. The results are illustrated in Fig. 4.

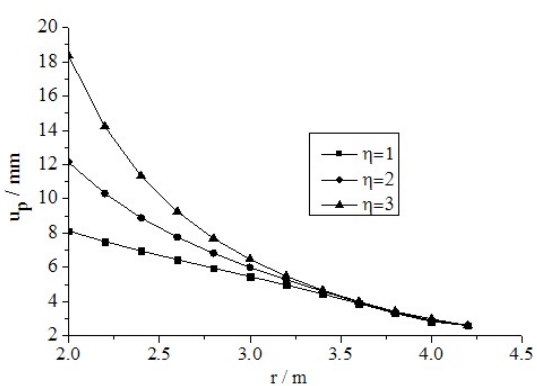

(a)

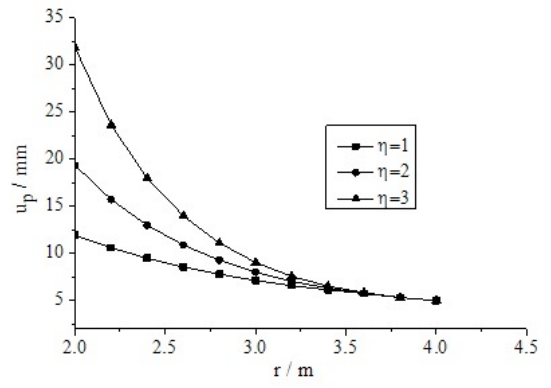

(b)

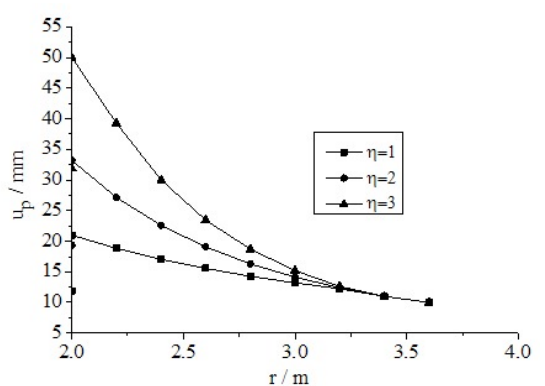

(c)

Fig. 4. Displacement distribution of roadway surrounding rock under the different side pressure coefficients and intermediate principal stresses. (a) $b=0 ; \theta=0^{\circ} ; \lambda=0.5$. (b) $b=0 ; \theta=0^{\circ} ; \lambda=1$. (c) $b=0 ; \theta=0^{\circ} ; \lambda=1.5$

Fig. 4 shows that the side pressure coefficient remains unchanged, and plastic displacement increases as shear dilatancy parameter increases. When shear dilatancy parameter is unchanged, plastic displacement increases as side pressure coefficient increases. When $\lambda=0.5$, the tunnel wall displacement in plastic zone increases by $63.5 \%$ as shear dilatancy parameter $\eta$ increases. When $\lambda=1$, tunnel wall displacement in plastic zone increases by $61.2 \%$ as shear dilatancy parameter $\eta$ increases. When $\lambda=1.5$, the 
tunnel wall displacement in the plastic zone increases by $58.4 \%$ as shear dilatancy parameter $\eta$ increases. Thus, shear dilatancy angle and side pressure coefficient significantly influence the plastic displacement. And also, they should be considered in supporting design of roadway surrounding rock.

\subsection{Influencing analysis of the different intermediate principal stress coefficients on the displacement of plastic zone}

The influences of side pressure coefficient and shear dilatancy parameter on the displacement of the plastic zone were previously analyzed, and then the influences of the different intermediate principal stress coefficients on plastic displacement would be discussed. Intermediate principal stress coefficient $b$ could be continuously taken as $0-1 . b=0$ expresses influence without considering intermediate principal stress, namely, Mohr-Coulomb criterion. In addition, $b=1$ represents maximum rock effect, and different $b$ values express different effects of intermediate principal stresses of rock and different yield criteria. The shear dilatancy parameter is $\eta=1$ when the side pressure coefficient $\lambda=1.0$. The displacement distribution results are depicted in Fig. 5.

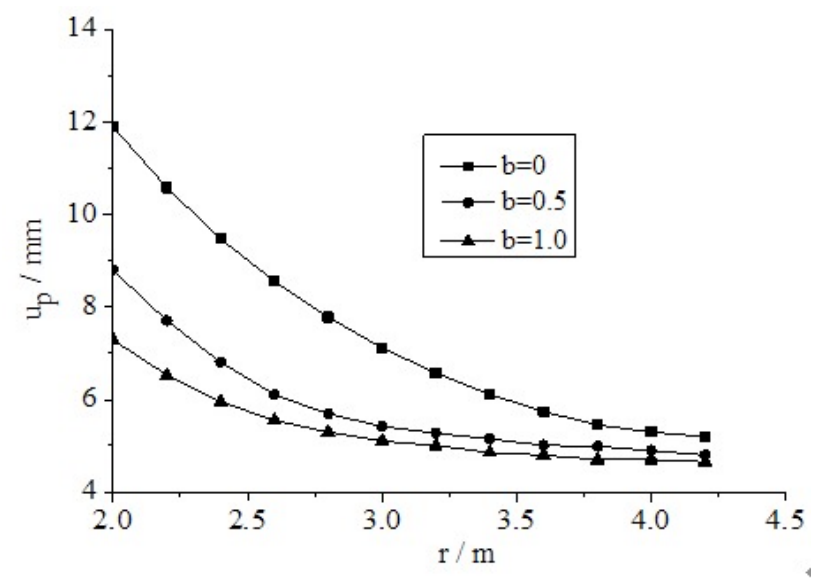

Fig. 5. Displacement distribution of plastic zone in roadway surrounding rock under different intermediate principal stresses

Fig. 5 presents the displacement distribution when $b$ is 0 , 0.5 , and 1.0. The tunnel wall displacement reduces from 11.8 when $b=0$ to $7.2 \mathrm{~mm}$ when $b=1$ by $35 \%$ while the intermediate principal stress coefficient increases. Thus, the effect of intermediate principal stress is significant.

\subsection{Field deformation monitoring}

The field monitoring and comparative analysis were conducted to analyze the influence laws of side pressure coefficient on the scope of plastic zone in roadway surrounding rock; these methods were performed for the plastic zone in surrounding rock of the floor roadways in the 1231 (1) and 1252 (1) working faces with the same engineering geological conditions and different side pressure coefficients in the eastern area of Panyi coal mine. The floor roadway in the 1252 (1) working face in the eastern area of Panyi coal mine is located at $20 \mathrm{~m}$ below the cutting hole of 1252 (1) working face as the covering roadway of the above cutting hole. The above mentioned floor roadways in the 1231 (1) and 1252 (1) working faces are under the same elevation. Stress relief method is used to measure the ground stresses of the two roadways. Both vertical stresses are 19.2 $\mathrm{MPa}$ and are influenced by conditions, including geological structure. The horizontal stresses of floor roadways in the 1231 (1) and 1252 (1) working faces are 18.5 and $35.8 \mathrm{MPa}$, respectively, and their side pressure coefficients are 0.96 and 1.86 , correspondingly. A borehole peering instrument is used to detect the failure conditions of surrounding rock in floor roadways in 1231 (1) and 1252 (1) working faces with the same burial depth. The influence of the side pressure coefficient on the scope of the plastic zone in roadway surrounding rock is analyzed. The boreholes peering layout of roadway surrounding rock is demonstrated in Fig. 6 . The failure conditions of surrounding rock in the two roadways are displayed in Figs. 7 and 8.

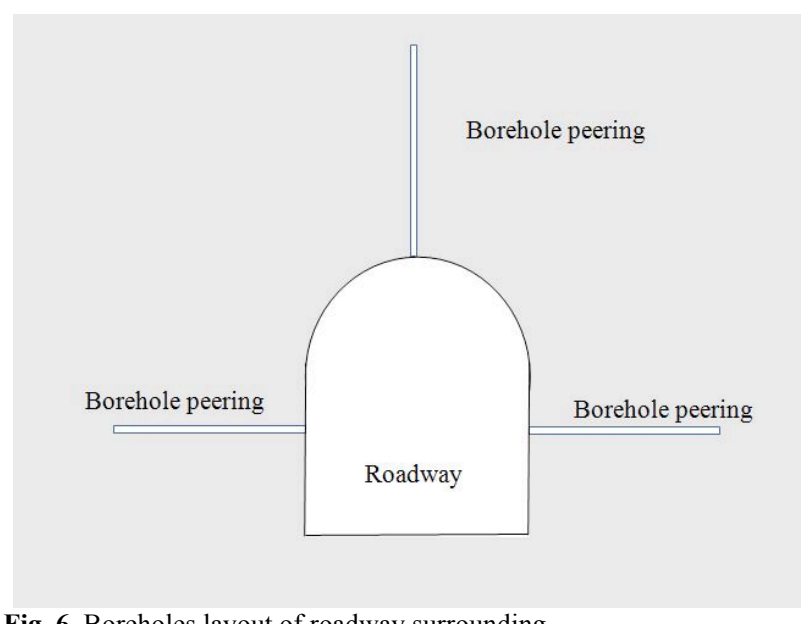

Fig. 6. Boreholes layout of roadway surrounding

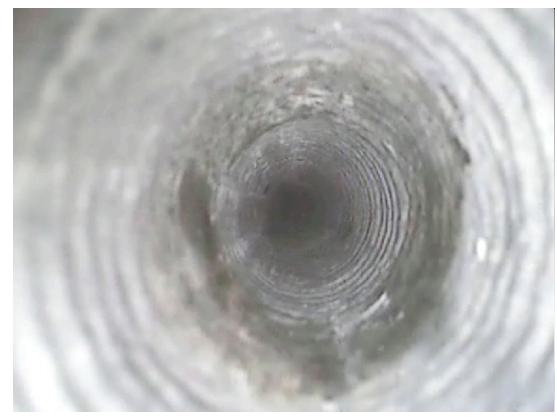

(a)

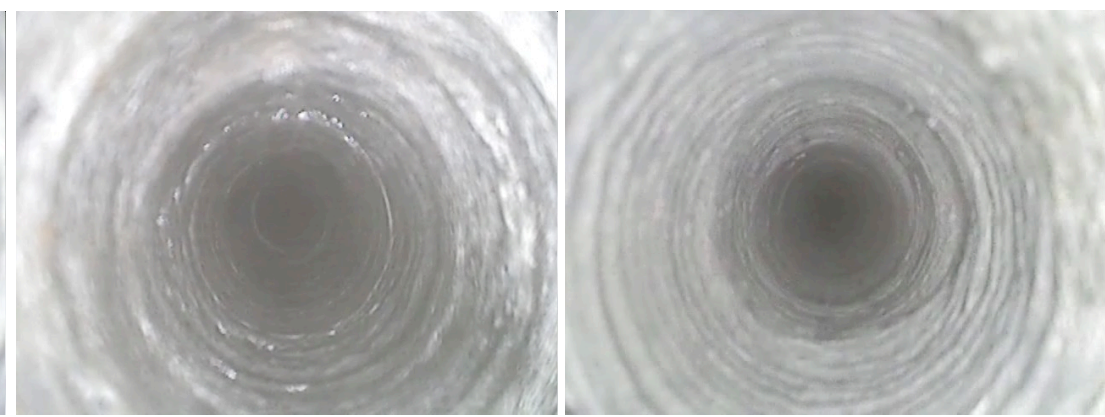

(b) (c)

Fig. 7. Boreholes peering view of the floor roadway in the 1231 (1) Working face. (a) Left rib. (b) Right rib. (c) Roof 


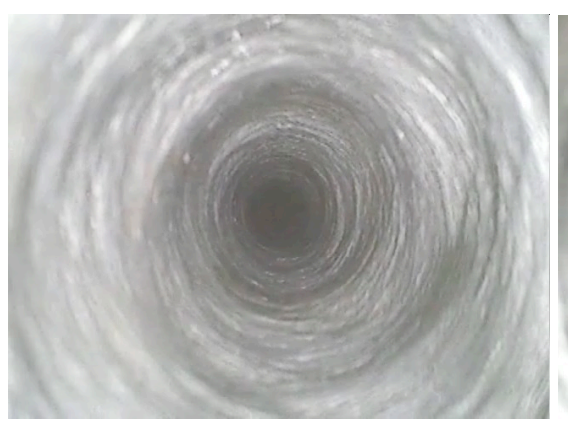

(a)

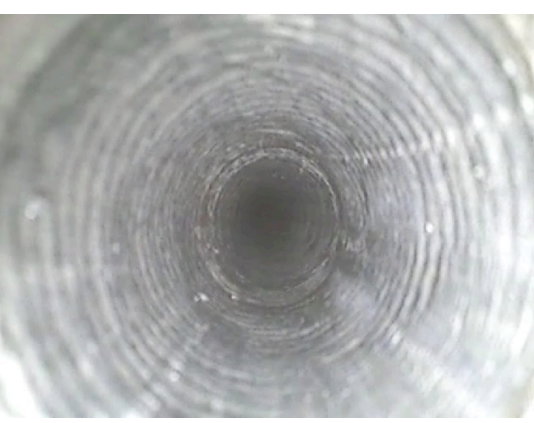

(b)

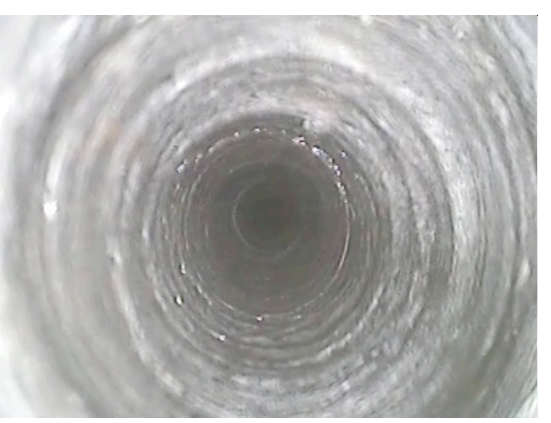

(c)

Fig. 8. Boreholes peering view of the floor roadway in 1252 (1) working face. (a) Left rib. (b) Right rib. (c) Roof

In Figs. 7 and 8, the damage and failure of the different degrees occurred in roadway surrounding rock. The dense crack failure at the shallow part of the roadway is serious. The cracks, especially the opening mode cracks, of the surrounding rock in the deep part are gradually reduced. The side pressure coefficient of the floor roadway in the 1231 (1) working face is 0.96 . The roof failure depth is $1.56 \mathrm{~m}$, and the failure depths of the left and right walls are 1.43 and 1.51 $\mathrm{m}$, respectively. The side pressure coefficient of the floor roadway in the 1231 (1) working face is 1.86 , and floor failure is severe. Boreholes peering shows that the failure degree was obviously higher in surrounding rock than in the two walls. Roof failure depth is $2.12 \mathrm{~m}$, and the failure depth of the left and right walls are 1.23 and $1.35 \mathrm{~m}$, correspondingly. Table 1 displays that the plastic failure zone of roadway obviously enlarges while the side pressure coefficient increases. The failure depth in the plastic zone along the $\theta=0^{\circ}$ direction is reduced by $12.24 \%$ and theoretically calculated value is reduced by $14.54 \%$ when the side pressure coefficient increases from 0.96 to 1.86 by comparing the measured and the theoretically calculated values of roadway failure depth. The failure depth of the plastic zone along the $\theta=90^{\circ}$ direction increases by $35.9 \%$, whereas the theoretically calculated value increases by $41.22 \%$. Thus, field monitoring is basically identical with theoretical calculation.

Table 1. Theoretically calculated and measured values of the failure depths of roadway surrounding rock

\begin{tabular}{|c|c|c|c|c|c|c|c|c|c|c|}
\hline $\begin{array}{l}\text { Roadway } \\
\text { name }\end{array}$ & $\begin{array}{c}\text { Side } \\
\text { pressu } \\
\text { re } \\
\text { coeffic } \\
\text { ient }\end{array}$ & $\begin{array}{c}\text { Side } \\
\text { pressure } \\
\text { coefficien } \\
\text { t }(\%)\end{array}$ & $\begin{array}{c}\text { Roof } \\
\text { failure } \\
\text { depth (m) }\end{array}$ & $\begin{array}{l}\text { Roof } \\
\text { failure } \\
\text { depth } \\
(\%)\end{array}$ & $\begin{array}{c}\text { Wall } \\
\text { average } \\
\text { failure } \\
\text { depth }(\mathbf{m})\end{array}$ & $\begin{array}{c}\text { Wall } \\
\text { average } \\
\text { failure } \\
\text { depth } \\
(\%)\end{array}$ & $\begin{array}{c}\text { Calculate } \\
\text { d value of } \\
\text { roof } \\
\text { failure } \\
\text { depth }(m)\end{array}$ & $\begin{array}{c}\text { Calcula } \\
\text { ted value } \\
\text { of roof } \\
\text { failure } \\
\text { depth } \\
(0 /)\end{array}$ & $\begin{array}{c}\text { Calculate } \\
\text { d value of } \\
\text { wall } \\
\text { failure } \\
\text { depth (m) }\end{array}$ & $\begin{array}{c}\text { Calcula } \\
\text { ted value } \\
\text { of wall } \\
\text { failure } \\
\text { depth } \\
(0 /)\end{array}$ \\
\hline $\begin{array}{c}\text { Roof } \\
\text { roadway in } \\
1231(1) \\
\text { working face }\end{array}$ & 0.96 & - & 1.56 & - & 1.47 & - & 1.48 & - & 1.65 & - \\
\hline $\begin{array}{c}\text { Roof } \\
\text { roadway in } \\
1252(1) \\
\text { working face }\end{array}$ & 1.86 & $(+) 93.75$ & 2.12 & $(+) 35.90$ & 1.29 & $(-) 12.24$ & 2.09 & $(+) 41.22$ & 1.41 & $(-) 14.54$ \\
\hline
\end{tabular}

\section{Conclusions}

The real stress state is hardly reflected by the assumed uniform stress mechanical environment of surround rock in the elastic-plastic analysis of roadway surrounding rock. A mechanical model of roadway surrounding rock under nonuniform stress conditions was established in this study based on unified strength theory to further analyze the stress and deformation distribution characteristics of roadway surrounding rock from the perspective of real stress response characteristics of surrounding rock. The floor roadway in the 1231 (1) working face in the eastern area of Panyi coal mine was taken as an example. The influences of the side pressure coefficient and intermediate principal stress on the scope of the plastic zone in surrounding rock were analyzed. The effect of shear dilatancy characteristics during the deformation and failure process of surrounding rock was discussed. And also, the field monitoring and verification of floor roadways in the 1231 (1) and 1252 (1) working faces in the eastern area of Panyi coal mine were implemented.
Based on the work completed, the following conclusions can be drawn:

(1) Side pressure coefficient is an important factor influencing the stress distribution and deformation of roadway surrounding rock. When intermediate principal stress coefficient remains unchanged, the radius of the plastic zone reduces as side pressure coefficient increases along the $\theta=0^{\circ}$ direction but increases along the $\theta=90^{\circ}$ direction. The scope of the plastic zone in the whole roadway surrounding rock is obviously different due to the difference of side pressure coefficient.

(2) The bearing capacity of roadway surrounding rock increases, and displacement deformation quantity gradually reduces when the intermediate principal stress coefficient increases. Intermediate principal stress could improve the stability of roadway surrounding rock.

(3) Plastic deformation increases when the shear dilatancy characteristic parameter $\eta$ increases. Therefore, field engineering technical personnel should consider the influence of the shear dilatancy characteristics of rock mass 
on the stability of surrounding rock in roadway supporting design.

(4) Field-drilled holes were used to monitor the deformation and failure of roadway surrounding rock. It has been verified that the results from theoretical calculation are consistent with the field test results, illustrating the reasonability of the proposed model.

Based on unified strength theory, the elastic-plastic mechanical knowledge was applied under the bidirectional anisobaric situation in this study. However, considering the extremely heavy engineering work load, only two roadways were selected in this study to perform the field test. The number of roadways in the field test should be added in future research to further verify and improve the mechanical model.

\section{Acknowledgements}

This study was supported by the National Natural Science Foundation of China (NO.51504005, NO.51304007), the University Science Research Project of Anhui Province (KJ2015A091), and the Anhui Provincial Natural Science Foundation (1408085MKL41, 1408085MKL42).

This is an Open Access article distributed under the terms of the Creative Commons Attribution Licence

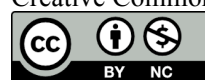

\section{References}

1. Kang, H.P., "Stress distribution characteristics and strata control technology for roadways in deep coal mines". Coal Science and Technology, 41(9), 2013, pp. 12-17.

2. He, M. C., Xie, H. P., Peng, S. P., Jiang, Y. D., "Study on rock mechanics in deep mining engineering". Chinese Journal of Rock Mechanics and Engineering, 24(16), 2005, pp. 2803-2813.

3. He, M. C., "Progress and challenges of soft rock engineering in depth". Journal of China coal society, 4(08), 2010, pp.1409-1417.

4. Bai, J. B.,Hou, C. J.,“Control principle of surrounding rocks in deep roadway and its application". Journal of China university of mining \& technology, (02)2006, pp. 145-148.

5.Zhang, N., Li, B. Y., Li, G. C., Qian, D. Y., Yu, X. Y., "Inhomogeneous damage and sealing support of roadways through thin bedded coal-rock crossovers". Journal of Mining \& Safety Engineering, (01)2013, pp. 1-6.

6. Shahrour, I., Khoshnoudian, F., Sadek, M., Mroueh, H., "Elastoplastic analysis of the seismic response of tunnels in soft soils". Tunnelling and Underground Space Technology, 25(4), 2010, pp. 478-482.

7. Maleki, M., Sereshteh, H., Mousivand, M., Bayat, M., "An equivalent beam model for the analysis of tunnel-building interaction". Tunnelling and Underground Space Technology, 26(4), 2011, pp. 524-533.

8. Kontoe, S., Zdravkovic, L., Potts, D.M., Menkiti, C.O., "On the relative merits of simple and advanced constitutive models in dynamic analysis of tunnels". Geotechnique, 61(10), 2011, pp. 815829.

9. Shalabi, F. I., Al-Qablan, H. A., Al-Hattamleh, O. H., "Elasto-plastic behavior of raghadan tunnel based on RMR and hoek-Brown classifications". Geotechnical and Geological Engineering, 27(2), 2009, pp. 237-248.

10.Madhavi L. G., Garaga, A., "Elasto-plastic analysis of jointed rocks using discrete continuum and equivalent continuum approaches". International Journal of Rock Mechanics and Mining Sciences, 53(7), 2012, pp. 56-63.

11.Zeng, K. H., Ju, H.Y., Zhang, C. G., "Elasto-plastic unified solution for displacements around a deep circular tunnel and its comparative analysis”. Rock and Soil Mechanics, 32(5), 2011, pp. 1315-1319.
12. Alejano, L.R., Rodríguez-Dono, A., Veiga, M., "Plastic radii and longitudinal deformation profiles of tunnels excavated in strainsoftening rock masses". Tunnelling and Underground Space Technology, 30(4), 2012, pp. 169-182.

13. Maleki, M., Mousivand, M., "Safety evaluation of shallow tunnel based on elastoplastic-viscoplastic analysis". Scientia Iranica, 21 (5), 2014, pp. 1480-1491.

14. Cantieni, L., Anagnostou, G., "On a paradox of elasto-plastic tunnel analysis". Rock Mechanics and Rock Engineering, 44(2), 2011, pp. 129-147.

15. Debernardi, D. ,Barla, G., "New viscoplastic model for design analysis of tunnels in squeezing conditions". Rock Mechanics and Rock Engineering, 42(2), 2009, pp. 259-288.

16. Fahimifar, A., Ghadami , H., Ahmadvand, M., "An elasto-plastic model for underwater tunnels considering seepage body forces and strain-softening behavior". European Journal of Environmental and Civil Engineering, 19(2), 2015, pp. 129-151.

17. Zhu, C. Q., Yin, Z. Q., Li, C. M., Feng, R.M., "Elastoplastic Analysis of Tunnel Surrounding Rocks based on the Statistical Damage Constitutive Model". Journal of Engineering Science and Technology Review, 9(3), 2016, pp. 27-34.

18. Zhu, C. Q., Yin, Z. Q., Li, C. M., Liu W. R., Fan, H., "Stability analysis of surrounding rocks in roadway considering strain hardening and dilatancy feature". China Safety Science Journal, 26(6), 2016, pp. 157-162.

19. Liu, Z. Q., Yu, D. M., "Elasto-plastic stress and displacement analytical solutions to deep-buried circular tunnels considering intermediate principal stress and dilation”. Engineering Mechanics, 29(8), 2012, pp. 289-295.

20. Sharan S. K., "Analytical solutions for stresses and displacements around a circular opening in a generalized Hoek-Brown rock". International Journal of Rock Mechanics and Mining Sciences, 2008, 45(1), 2008, pp. 78-85.

21. Xu S. Q., Yu M. H., "The effect of the intermediate principal stress on the ground response of circular openings in rock mass". Rock Mechanics and Rock Engineering, 39(2), 2006, pp. 169-181.

22. Zhao Z. H., Wang W. M., Wang L., "Response models of weakly consolidated soft rock roadway under different interior pressures considering dilatancy effect". Journal Central South University, 20(2), 2013, pp. 3736-3744. 